This item was submitted to Loughborough's Research Repository by the author.

Items in Figshare are protected by copyright, with all rights reserved, unless otherwise indicated.

\title{
Women's economic activity trajectories over the life course: Implications for the self-rated health of women aged 64+ in England
}

PLEASE CITE THE PUBLISHED VERSION

https://doi.org/10.1136/jech-2014-204777

\section{PUBLISHER}

BMJ Publishing Group

VERSION

AM (Accepted Manuscript)

\section{PUBLISHER STATEMENT}

This work is made available according to the conditions of the Creative Commons Attribution-NonCommercialNoDerivatives 4.0 International (CC BY-NC-ND 4.0) licence. Full details of this licence are available at: https://creativecommons.org/licenses/by-nc-nd/4.0/

\section{LICENCE}

CC BY-NC-ND 4.0

\section{REPOSITORY RECORD}

Stone, Juliet, Maria Evandrou, Jane Falkingham, and Athina Vlachantoni. 2019. "Women's Economic Activity Trajectories over the Life Course: Implications for the Self-rated Health of Women Aged 64+ in England". figshare. https://hdl.handle.net/2134/36474. 
Women's economic activity trajectories over the life course: implications for the self-rated health of women aged 64+ in England

Juliet Stone $^{1 a}$, Maria Evandrou ${ }^{1,2}$, Jane Falkingham ${ }^{1}$ and Athina Vlachantoni ${ }^{1,2}$.

${ }^{1}$ ESRC Centre for Population Change, University of Southampton, UK.

${ }^{2}$ Centre for Research on Ageing, University of Southampton, Southampton, UK

a Corresponding author:

Dr. Juliet Stone

Centre for Population Change

School of Social Sciences

Room 2043, Building 58

University of Southampton

Highfield,

Southampton S017 1BJ

Tel: (+44) 2380593071 ;

Fax: (+44) 2380593131.

Email: j.stone@soton.ac.uk

Keywords: Women; England; Life course; Work; Family

Word count: 3,830 


\section{ABSTRACT \\ Background}

Previous research has highlighted the importance of accumulated life course labour market status and balancing multiple roles for understanding inequalities in health in later life. This may be particularly important for women, who are increasingly required to balance work and family life in liberal welfare contexts such as Britain.

\section{Methods}

This study analyses retrospective life history data for 2,160 women aged 64+ (born 1909-1943) from the English Longitudinal Study of Ageing, collected in 2006-7 as part of an ongoing panel study. Optimal matching and cluster analysis are used to produce a taxonomy of women's life-course economic activity trajectories based on their experiences between ages 16 and 64 years. This classification is then used in logistic regression analysis to investigate associations with self-rated health in later life.

\section{Results}

A set of five trajectories emerge as the dominant patterns of women's economic activity over the life course for those cohorts of English women born prior to 1943: 1. Full-time workers; 2. Family carers; 3. Full-time returners; 4. Part-time returners; 5. Atypical/inactive. Regression analyses show that women who experience defined periods of full-time work both before and after focusing on family life appear to have the most favourable later life health outcomes.

\section{Conclusions}

The findings are discussed with reference to the accumulation of social and economic resources over the life course and the balancing of multiple roles in work and family domains. In conclusion, the development of policies that facilitate women, if they wish, to successfully combine paid employment with family life, could have a positive impact on their health in later life. 


\section{WHAT IS ALREADY KNOWN ON THIS SUBJECT?}

Previous research on women's life-course economic activity status and later health has tended to focus on distinct periods of life, such as the period around family formation, or has used summary measures of, for example, accumulated labour market experience. Evidence documenting entire trajectories of economic activity, incorporating the sequence and timing of multiple role experiences, and how this relates to women's later health, is lacking for Britain.

\section{WHAT THIS STUDY ADDS}

This study shows that the dominant types of economic activity trajectories experienced by older women have remained relatively limited despite rapid societal changes over the twentieth century. The findings suggest that sequential experiences of multiple roles in work and family domains of life are beneficial to later health and this is only partly explained by accumulated economic and social resources. Policies which support women in combining economic and social roles over the life course may therefore produce benefits in terms of later life health outcomes, as well as maximising women's pension contributions over their life course. 


\section{INTRODUCTION}

\section{Background}

In an ageing population, maximising healthy life expectancy is a key objective both at an individual and population level. In Britain, evidence suggests that health inequalities persist across the life course and into older age [1, 2]. In order to understand the diversity of circumstances among people currently in older age, it is important to consider their preceding life course [3]; this may include inequalities in life chances that accumulate to produce inequalities in later life [4], the effects of life-course labour market activity on current financial status [5], and continuity of social activities and networks formed during earlier life [3]. Existing research shows that women's work and family histories shape their economic resources in later life [5, 6], although mediated in part by their welfare context [7]. This may, in turn, reinforce health inequalities among the older population.

Taken together, these factors highlight the importance of describing patterns of women's life-course economic activity over the twentieth century and their potential influence on health in later life. To inform policies that address this issue, there is a need to increase understanding of the processes by which diseases and disorders develop throughout people's lives; for example the extent to which health status presents an accumulated advantage or disadvantage across the life course [8] or the impact of balancing work and family life upon later health outcomes [9].

\section{Theoretical framework}

This paper considers three inter-related theoretical standpoints to investigate women's economic activity over the life course and its relationship with health in later life: 1) Accumulated advantage/disadvantage over the life course; 2) Life course theory and the idea that the timing, sequence and context of key life course transitions and exposures can affect subsequent outcomes, such as health; and 3) The notion of multiple roles when considering women's economic activity trajectories and the roles they inhabit within work and family domains.

\section{Accumulation of advantage/disadvantage}

The accumulation of advantage/disadvantage has been proposed as a key factor contributing to persistent (health) inequalities. The hypothesis states that social and material experiences over one's life course, including 
life-time labour market experiences, may influence health both directly via the accumulation of financial and material resources and indirectly via the impact of, for example, unemployment on mental health [10]. In lifecourse epidemiology, an accumulation model often assumes a dose-response relationship between exposure to "risks" and development of disease [11,12] and the sequence of exposures is essentially immaterial [13], although "chains" or clusters of disadvantage or advantage may occur [14]. Many studies of associations between life-course exposures and later health have been informed by an accumulation model [15-18] but frequently use information from only two or three points in time, which limits the extent to which the life course can be studied as a dynamic process. In contrast, a more sociological conceptualisation of the life course explicitly emphasises the sequence and timing of exposures.

\section{Life course transitions, trajectories and historical context}

Central to the life course paradigm are the concepts of trajectory and transition. Transitions, embedded within trajectories, are particularly related to "the adaptive problems of entry and exit from a single role" (p.24) [19], including changes in economic activity. A trajectory links states over time and takes into account the duration between changes in state [20]. The interdependence of different trajectories - such as work, family and health within and across an individual life course is also emphasised. The present study focuses on trajectories of economic activity, which may be more complex for women than men due to the conflicting demands of work and family. A life course approach also considers how historical time can interacts with these trajectories and transitions, reflecting the intersection of personal biographies with social (normative) timelines and sociohistorical context [21]. For women born in the first half of the twentieth century in Britain, their experiences of labour market participation and family life must be considered in the context of a period of rapid societal change [22], including the growth of individualism; the de-standardising of normative pathways through the life course; changes in partnership and family formation; and increasing social and spatial inequalities [23].

\section{Multiple role theory}

The relationship between women's economic activity and health is often discussed in terms of two competing theories relating to inhabiting different roles in different domains of life [24, 25]. The 'role strain' hypothesis suggests that the competing and accumulating demands associated with occupying multiple roles in working and family life can result in increased strain and stress levels, with a detrimental effect on women's health [25- 
27]. The 'role accumulation' hypothesis suggests that multiple roles enhance women's access to financial, social and emotional resources and hence have a positive impact on their health and wellbeing [27-29]. These theoretical and empirical approaches generally take a cross-sectional approach to understanding multiple roles and health, however the longitudinal accumulation of multiple role experiences could also impact on later health outcomes. Accumulated life-course labour market status has been shown to have strong links to health for men [10], while an individual's reproductive history can also affect the later health of both men and women , with early entry into parenthood and high levels of parity associated with poor health [30, 31].

In the UK, recent work using the British Household Panel Survey [32] has shown that work-family histories can affect the propensity to remain in work after pension age, and that labour market activity over the life course can influence financial status in later life [5]. Work from the USA also indicates that occupying multiple roles in earlier adult life shows a positive association with later health [33]. Recently, European data have become available that allow researchers to examine women's entire adult life course by utilising retrospectively reported life histories [34, 35]. However, much previous work on women's economic activity trajectories in relation to their later health has focussed on particular age groups or cohorts of women, and used relatively basic summary measures, such as the number of years spent in paid employment.

\section{Aims}

Using data from the English Longitudinal Study of Ageing (ELSA) life histories, the present study builds on existing work to incorporate the sequence, timing and duration of economic activity experiences over the life course using optimal matching analysis. The aims of the paper are to 1) produce and describe a taxonomy of the trajectories of economic activity among women in England who are currently in later life and 2) investigate the association between these trajectories and health in later life. The outcome measure is self-rated health (SRH), which represents a 'global' measure of health and has the advantage of identifying individual experiences of poor health regardless of precise clinical diagnoses. This is important in observational studies, as reported in the present paper, where the prevalence of specific health conditions may be relatively low. Nevertheless, SRH is consistently shown to predict mortality [36] and to correlate with both physical and mental health [37] and therefore represents a useful proxy for these more objective indicators of health status. 


\section{DATA AND METHODS}

\section{The English Longitudinal Study of Ageing}

ELSA collects data from a representative sample of the English population aged 50 and over relating to their health and disability, economic circumstances, social participation, networks and well-being. The original sample of $\sim 12,000$ respondents was drawn from the Health Survey for England. In 2006-7 (ELSA Wave 3), respondents completed a life history interview that provides detailed information about their work, family and residential histories. A life-grid method was used to collect data from different life-course domains simultaneously using a calendar, anchored by key external events in wider society [38]. By age 64 years, $95 \%$ of women were no longer in paid employment; thus by this age threshold it could be assumed that the life histories would capture the full working life of the majority of women. Among 5,476 female respondents at Wave 3, a total of 2,605 were aged 64 years or older at interview. Of these women, 2,186 (84\%) completed the life history interview; and 2,162 provided complete information on their economic activity between ages 16 and 64. Two cases were excluded due to missing data on SRH or age at interview, providing a final sample of 2,160 women aged 64-98 years at interview (with life course information spanning the period 1925-2007). The analyses are weighted to account for differential nonresponse between the main Wave 3 interview and the Life History Interview and for overall nonresponse to the main interview [39].

The life history data are used to reconstruct the sample's work histories from ages 16-64 years, coding their economic activity annually to produce a sequence of 49 time-points per individual. Economic activity is classified using a six-category variable:

1. Employed full-time

2. Employed part-time

3. Looking after home/family

4. Unemployed/other inactive

5. In education/training

6. Retired 


\section{Optimal matching and cluster analysis}

Optimal matching analysis (OMA) is applied to classify the patterns of economic activity experienced by women over their lives. OMA, a type of sequence analysis, was introduced into sociology towards the end of the twentieth century [40] and differs from more commonly used methods such as event history analysis by providing a means to examine complete sequences of data simultaneously, with entire trajectories used as the basic unit of analysis. In brief, OMA works by measuring the "distance" between pairs of sequences, the distance being based on the minimum number of operations (insertion, deletion and substitution of states) needed to turn one sequence into the other [41]. The output of OMA is a matrix that specifies the 'distance' between each pair of sequences, which can then be used as the basis for additional analysis to identify distinct groups within the data. Trajectories are matched both on the ordering of particular sub-sequences of events and transitions, and on their timing within the trajectories as a whole. OMA was carried out using the SQOM command in STATA version 12, followed by cluster analysis using Ward's linkage, which produces clusters based on a weighted average of distances between variables.

\section{Logistic regression analysis - self-rated health}

Using the taxonomy of life-time economic activity status produced using the OMA and cluster analysis, the second stage of the research involves binary logistic regression analysis to investigate the value of the taxonomy in predicting SRH in later life, measured using a five-category response. For subsequent analyses, SRH is dichotomised as 'Good' (very good/good) or 'Poor' (fair/bad/very bad). Overall, 785 women (38.2\%) reported fair/poor SRH. The results from four nested regression models are presented. Model 1 examines the relationship between trajectories of economic activity and SRH, controlling for age at interview only. Model 2 investigates whether the trajectory classification provides additional explanatory value beyond reflecting the accumulation of economic and financial resources. Three measures of accumulated economic resources are considered: 1. Woman's own occupational class at interview (using the three-category version of the National Statistics Socioeconomic Classification [NSSEC]), as a measure of labour market advantage/disadvantage. The NSSEC is the standard measure of occupational social class used in contemporary UK official statistics and surveys and is based on the Goldthorpe Schema [42]; 2. Housing wealth at interview as a measure of life-course accumulation of financial capital; and 3. Percentage of working life in part-time work. Part-time work is used as a proxy for individual labour market participation over the life course but also reflects accumulation of 
earnings and pension entitlements in later life, including the 'part-time penalty' associated with motherhood that means pro rata earnings are lower for part-time than full-time work [43]. To evaluate the hypothesis that the accumulation of multiple roles over the life course may influence later health via the accumulation of both financial and social resources [33], model 3 adds indicators of family resources that may reflect experiences of social integration: current marital status and total number of children. Finally, to control for household circumstances, model 4 controls for partner's current occupational class for a subgroup of 923 women who have a co-resident partner at the wave 3 interview.

\section{RESULTS}

\section{Optimal matching and cluster analysis}

Based on the exploratory analysis, a five-cluster solution was judged to be the best in distinguishing different trajectories of economic activity in this sample. Figure 1 shows a summary of the life-course trajectories of economic activity experienced by women in each cluster. Table 1 provides descriptive statistics regarding the current and life-course characteristics of the groups. The clusters are named as follows:

1. Full-time workers (23\% of the sample);

2. Family carers (20\%);

3. Full-time returners (23\%);

4. Part-time returners (25\%); and

5. Atypical/inactive (8\%).

\section{Classification and characteristics of trajectories}

Table 1 comprises a summary of the descriptive characteristics of the five clusters. Cluster 1 (full-time workers) shows a group of older women who spent the majority of their working lives in full-time employment. Compared with the other clusters, this group exhibits a significantly lower mean number of children $(\mathrm{p}<0.001)$ and partners $(\mathrm{p}<0.05)$, further suggesting relatively limited engagement with family life. In contrast, cluster 2 (family carers) represents women who spent the majority of their lives looking after a home/family. Clusters 3 (full-time returners) and 4 (part-time returners) demonstrate two groups of women who experienced a period looking after a home/family but then returned to either full-time or part-time work. Cluster 5 (atypical/inactive) 
shows a small group of women ( $8 \%$ of the total sample) who for a substantial proportion of their adult lives do not define themselves as active in either work or family, but instead are classified as unemployed or otherwise economically inactive (mostly long-term sick or disabled).

Pairwise comparisons of the five clusters indicate that on average, full- and part-time returners are significantly younger than women classified as full-time workers or family carers $(\mathrm{p}<0.01)$. Together, full- and part-time returners account for half of the women included in the analyses. These two groups are similar in many respects - for example, in terms of their mean age, age when they left education, age at first marriage and birth, and mean number of children (Table 1). Apart from the different balance of full- and part-time work, the other main difference is that full-time returners are more advantaged in terms of their (current) occupational class, being twice as likely to be in NSSEC class 1 (higher managerial/professional) as are part-time returners $(25.6 \%$ versus $12.4 \% ; \mathrm{p}<0.001)$. 


\begin{tabular}{|c|c|c|c|c|c|c|}
\hline & \multicolumn{5}{|c|}{ ECONOMIC ACTIVITY TRAJECTORY CLUSTER } & \multirow[b]{3}{*}{ Total } \\
\hline & \multirow{2}{*}{$\begin{array}{l}1 \\
\text { Full-time } \\
\text { workers }\end{array}$} & \multirow{2}{*}{$\begin{array}{l}2 \\
\text { Family } \\
\text { carers }\end{array}$} & \multirow{2}{*}{$\begin{array}{l}3 \\
\text { Full-time } \\
\text { returners }\end{array}$} & \multirow{2}{*}{$\begin{array}{l}4 \\
\text { Part-time } \\
\text { returners }\end{array}$} & \multirow{2}{*}{$\begin{array}{l}5 \\
\text { Atypical/ } \\
\text { inactive }\end{array}$} & \\
\hline & & & & & & \\
\hline Weighted \% of sample & 23.4 & 20.4 & 23.4 & 24.6 & 8.3 & 100 \\
\hline Weighted \% with fair/poor SRH & 41.1 & 40.6 & 32.7 & 34.9 & 50.5 & 38.3 \\
\hline Mean age at interview & 76.0 & 76.8 & 73.5 & 74.1 & 75.2 & 75.0 \\
\hline Mean age left education & 20.0 & 15.4 & 16.9 & 15.7 & 16.1 & 17.0 \\
\hline \multicolumn{7}{|l|}{ Mean years of life in employment: } \\
\hline Total & 36.0 & 9.4 & 30.5 & 28.9 & 16.8 & 26.0 \\
\hline Full-time & 33.1 & 7.8 & 25.3 & 8.1 & 11.6 & 18.2 \\
\hline Part-time & 2.9 & 1.6 & 5.2 & 20.8 & 5.2 & 7.8 \\
\hline Mean age at retirement & 58.7 & 62.0 & 60.0 & 58.8 & 49.4 & 58.8 \\
\hline Mean age at first marriage & 25.8 & 23.3 & 22.0 & 22.4 & 22.4 & 23.2 \\
\hline Mean number of partners & 1.0 & 1.1 & 1.2 & 1.1 & 1.2 & 1.1 \\
\hline Mean age at first birth & 26.9 & 25.8 & 24.3 & 25.1 & 24.6 & 25.3 \\
\hline Mean age at last birth & 31.6 & 32.0 & 29.6 & 30.7 & 30.5 & 30.8 \\
\hline Mean number of children & 1.5 & 2.5 & 2.5 & 2.4 & 2.3 & 2.2 \\
\hline \multicolumn{7}{|l|}{$\%$ in NSSEC group: } \\
\hline 1 Higher managerial/professional & 32.9 & 13.1 & 25.6 & 12.4 & 14.9 & 20.6 \\
\hline 2 Intermediate & 29.5 & 28.3 & 29.9 & 23.8 & 31.6 & 28.1 \\
\hline 3 Routine/manual & 34.6 & 48.8 & 43.9 & 62.0 & 47.3 & 47.5 \\
\hline 4 Long-term unemployed & 3.0 & 9.8 & 0.5 & 1.9 & 6.3 & 3.8 \\
\hline \multicolumn{7}{|l|}{ Current partner ${ }^{1}$ - $\%$ in NSSEC group: } \\
\hline 1 Higher managerial/professional & 42.9 & 39.1 & 36.1 & 38.1 & 38.2 & 38.7 \\
\hline 2 Intermediate & 21.3 & 19.5 & 22.6 & 19.5 & 18.0 & 20.5 \\
\hline 3 Routine/manual & 35.8 & 39.1 & 40.8 & 42.0 & 43.9 & 40.1 \\
\hline 4 Long-term unemployed & 0.0 & 2.3 & 0.5 & 0.5 & 0.0 & 0.7 \\
\hline
\end{tabular}

note: descriptives refer to characteristics measured for ages 0-60 (employment, 16-60).

1 Partner characteristics only available for respondents who have a co-resident partner at wave 3 who also provides a valid interview response $(n=923)$ 


\section{Explanatory analysis - predicting poor self-rated health}

Table 2 shows the results of logistic regression analysis predicting poor SRH. The results from model 1, controlling only for age at interview, suggest that women classified as full-time and part-time returners are significantly less likely to have poor SRH than full-time workers. The atypical/inactive group are more likely to have poor health, which likely reflects the high proportion of women economically inactive due to long-term sickness. When indicators of accumulated economic/financial resources are included (model 2), housing wealth shows a particularly strong relationship with SRH, with the odds for poor SRH decreasing as wealth increases. However, women classified as full-time returners remain significantly less likely to be in poor health than the reference group. In model 3, indicators of potential family resources are added (marital status and parity), but show no significant association with SRH. In this model, the association between being a 'full-time returner' and reduced odds for poor health remains statistically significant at the 5\% level. In model 4, the partner's NSSEC is added for the subgroup of older women with a current co-resident partner. Although the association between the full-time returners group and reduced odds for poor SRH is no longer statistically significant (reflecting, in part, the reduced sample size) the odds ratios still indicate that this group is doing best in terms of their current SRH. 
Table 2: Results from logistic regression analysis predicting poor self-rated health at interview in Wave 3 , women aged $64+$ at interview.

$\begin{array}{llll}\text { Model } 1 & \text { Model2 } & \text { Model } 3 & \text { Model } 4\end{array}$

Cluster group (ref 1. Full-time workers)
2. Family carers
3. Full-time returners
4. Part-time returners
5. Atypical/inactive

Age group at interview (ref 64-69)

70-79

$80+$

NSSEC (ref 1: Higher managerial/professional)

2. Intermediate

3. Routine/manual

4. Long-term unemployed

Housing wealth band (ref none)

$£ 1-149999$
$£ 150-299999$
$£ 300-449999$
$£ 450000+$

$\%$ of life in part-time work

Number of children (ref none)

1

2

$3+$

Current marital status (ref never married)

Married (first marriage)

Remarried

Divorced

Widowed

Partner's NSSEC (ref 1: Higher managerial/professional)

2. Intermediate

$\begin{array}{llll}1.26^{*} & 1.15 & 1.18 & 1.18 \\ 1.58^{* * *} & 1.29^{\dagger} & 1.33^{\dagger} & 1.52\end{array}$

$\begin{array}{llll}0.96 & 0.89 & 0.94 & 1.24 \\ 0.73^{*} & 0.69^{*} & 0.71^{*} & 0.77 \\ 0.79 \dagger & 0.77 & 0.82 & 0.89 \\ 1.50^{*} & 1.43^{\dagger} & 1.47^{\dagger} & 1.87^{\dagger}\end{array}$

$1.58 * * *$

$\begin{array}{lll}0.90 & 0.91 & 0.96 \\ 1.75^{* * *} & 1.74^{* * *} & 1.85^{*} \\ 1.59 & 1.61 & 3.34^{\dagger}\end{array}$

$\begin{array}{lll}0.71^{*} & 0.71^{*} & 0.60^{\dagger} \\ 0.47^{* * *} & 0.47^{* * *} & 0.43^{* * *} \\ 0.32^{* * *} & 0.32^{* * *} & 0.28^{* * *} \\ 0.20^{* * *} & 0.20^{* * *} & 0.15^{* * *} \\ 0.99 & 0.99 & 1.00\end{array}$

$0.90 \quad 1.00$

$0.83 \quad 0.67$

$0.94 \quad 0.71$

$0.99 \quad 0.63$

$1.39 \quad 1.14$

$0.98 \quad 0.97$

0.99

3. Routine/manual

4. Long-term unemployed

\begin{tabular}{lllll}
\hline$N$ & 2160 & 2160 & 2160 & 923 \\
\hline
\end{tabular}

Exponentiated coefficients

${ }^{\dagger} p<0.10,{ }^{*} p<0.05,{ }^{* *} p<0.01,{ }^{* * *} p<0.001$ 


\section{DISCUSSION}

Work and family opportunities for women in English society during the second half of the twentieth century had ostensibly become more diverse via, for example, participation in the labour market and access to contraception $[22,23,44]$. However, in the present study a relatively limited set of trajectories emerged that encapsulate the dominant patterns of women's economic activity over the life course during this period. To understand why this is the case requires consideration of how this historical context interacts with women's chronological and social time-lines. Despite the considerable societal changes that occurred during their lifetimes most of the women in this study, born between 1909and 1943, would have already been young adults or in mid-life by the 1960s, when many of these changes began to emerge. Therefore, at least in terms of family formation, these women were likely to already have embarked upon the 'traditional' route of marriage followed by childbearing. This may in part explain why the trajectories of economic activity were not more heterogeneous, and supports the argument that life-course trajectories may often be limited by social, cultural or structural 'norms' [19].

The findings further suggest that women's trajectories of economic activity have an impact on their SRH in later life. In contrast to previous findings for men [10], the findings indicate that for women, being in full-time paid employment across the life course is not necessarily good for their later health. This does, however, support previous evidence for women in the USA indicating that labour-force participation over the life course does not necessarily promote healthy ageing [33]. Women who experience distinct periods of full-time work and periods focussed on looking after a family appear to have the most favourable outcomes.

There is some support for an accumulation model, given that housing wealth shows a relatively strong and negative linear relationship with the risk of poor SRH in later life. However, a simple 'dose-response' relationship between accumulation of resources and health does not provide a full explanation of the association between women's economic activity trajectories and health. Even when controlling for indicators of accumulated financial and social resources, significant associations between life-course economic activity and SRH remain. The classification of economic activity trajectories incorporating both the duration and the pattern of work and family statuses across women's lives adds explanatory value in predicting SRH in later life. The results therefore provide support for both a life-course perspective, emphasising the sequence and timing of 
experiences within interrelated work and family trajectories, and a longitudinal multiple role perspective that considers lifetime experiences of occupying particular roles in work and family life.

Previous work suggests that associations between multiple role occupancy and health are highly dependent upon the nature of such roles and health outcomes, and there is no clear consensus as to whether the overall effects on health are positive or negative $[45,46]$. Perhaps combining work and family confers short-term detrimental effects on health, but long-term benefits due to opportunities to accumulate resources that have an impact throughout life into older age. This is supported by the findings presented here in that the most favourable outcomes were observed among women who took time out of full-time work to concentrate on family life, before returning to employment at a later date. Such women would tend to experience multiple roles sequentially rather than simultaneously, therefore avoiding the 'role stress' associated with concurrent multiple role occupancy. The present study also suggests that women who consistently occupy one 'major role' throughout their life course are disadvantaged in terms of their later health compared with those who experience distinct periods of time focused on work and family domains, and provides tentative support for the 'role accumulation' hypothesis.

\section{Limitations}

When analysing data from observational studies such as ELSA it is important to be mindful of biases that might arise from sample selection. For the present study, a particular concern is selection bias based on both health and economic activity, such that those who are unwell and/or socioeconomically disadvantaged being underrepresented in the sample. Cross-sectional weights in the ELSA dataset, designed to account for differential non-response in each wave and calibrated to match 2006 household population estimates for England from the Office for National Statistics, are helpful in reducing the impact of non-response to some extent. Unfortunately, no information is available on life course experiences of health and illness, therefore it is difficult to assess the possibility of reverse causation, i.e. whether poor health preceded transitions in economic activity. However, if we assume that women who are socioeconomically disadvantaged and have poor self-rated health are under-represented in the sample due to non-response, this is likely to result in underestimation of health inequalities. Therefore, the present study likely provides conservative estimates 
of the associations of interest and this may also in part explain why the observed associations were modest in magnitude. In addition, there is a related issue of attrition from the sample longitudinally, which is also to an extent dealt with by using the cross-sectional weights. To test the impact of attrition, a twostage selection model was estimated, providing reassurance that loss to follow-up did not have a significant impact on the substantive findings. Further details of this selection modelling can be found in the supplementary online material.

Cautious consideration is also required as a range of other indicators about work and family life, such as the nature of women's work, their earnings, and the spacing of childbearing are not included in this analysis. A limited set of covariates was included to measure accumulated resources, and additional effects not controlled for cannot be ruled out. In operationalising multiple roles, only work and looking after a home and family were considered. Other roles outside these domains might also be important however - in particular, the additional 'role strain' that might arise from informal caring for an ill spouse or surviving parents. Nevertheless, the findings show the potential of such work to make a valuable contribution in providing, for England, a new classification of women's life-course economic activity trajectories that takes the timing, sequence and duration of changing labour market status into account and can, in turn, help predict women's health and wellbeing in later life.

\section{Conclusions}

Despite the more active and varied role of women in the labour market in the second half of the twentieth century, current cohorts of older women have still followed a relatively narrow range of economic activity trajectories. This might reflect continuing structural constraints and cultural expectations regarding work and family for women during this period. The findings suggest that policies that allow women, if they wish, to successfully combine paid employment with family life may have a positive impact on their health in later life. Such policies might include increasing the provision of affordable childcare. In turn, policies which encourage the combination of multiple roles over the life course may also produce benefits for women's pension contributions and broader economic resources in later life, which can further increase women's choice over 
their life trajectory. Given that SRH is consistently shown to be a significant predictor of mortality, the findings may also have wider implications for the longevity and the ageing of future cohorts of women in England. 


\section{ACKNOWLEDGEMENTS}

The data were made available through the UK Data Archive. ELSA was developed by a team of researchers based at the NatCen Social Research, University College London and the Institute for Fiscal Studies. The data were collected by NatCen Social Research. The funding is provided by the National Institute of Aging in the United States, and a consortium of UK government departments co-ordinated by the Office for National Statistics. The developers and funders of ELSA and the Archive do not bear any responsibility for the analyses or interpretations presented here.

COMPETING INTERESTS: none

\section{FUNDING}

This work was supported by the Economic and Social Research Council (ESRC) [grant number RES-625-280001] which funds the ESRC Centre for Population Change (CPC) where this study was carried out. CPC is a joint initiative between the Universities of Southampton, St. Andrews, Dundee, Edinburgh, Stirling and Strathclyde, in partnership with the Office for National Statistics (ONS) and the General Register Office Scotland (GROS) (now the National Records of Scotland, NRS). The findings, interpretations, and conclusions expressed in this study are entirely those of the authors and should not be attributed in any manner to ONS or GROS/NRS. 


\section{REFERENCES}

1. Grundy E, Holt G. Adult life experiences and health in early old age in Great Britain. Social Science \& Medicine 2000; 51(7):1061-1074.

2. Marmot MG, Allen J, Goldblatt P, Boyce T, McNeish D, Grady M et al. Fair society, healthy lives: Strategic review of health inequalities in England post-2010. 2010.

3. Arber S, Davidson K, Ginn J. Changing approaches to gender and later life. Gender and ageing: Changing roles and relationships 2003;1-14.

4. Spencer N. Explaining the social gradient in smoking in pregnancy: early life course accumulation and crosssectional clustering of social risk exposures in the 1958 British national cohort. Social Science \& Medicine 2006; 62(5):1250-1259.

5. Glaser K, Nicholls M, Stuchbury R, Price D, Gjonca E. Life course influences on poverty and social isolation in later life: a review. 2009. Manchester, Equality and Human Rights Commission.

6. Joshi H. The cash opportunity costs of childbearing: an approach to estimation using British data. Population Studies $1990 ; 44(1): 41-60$.

7. Sefton T, Evandrou M, Falkingham J, Vlachantoni A. The relationship between women's work histories and incomes in later life in the UK, US and West Germany. Journal of European Social Policy 2011; 21(1):20-36.

8. Hareven TK, Trepagnier B. Families, history, and social change: life course and cross-cultural perspectives. Westview Press Boulder, CO; 2000.

9. Kotler P, Wingard DL. The effect of occupational, marital and parental roles on mortality: the Alameda County Study. American Journal of Public Health 1989; 79(5):607-612.

10. Bartley M, Plewis I. Accumulated labour market disadvantage and limiting long-term illness: data from the 19711991 Office for National Statistics' Longitudinal Study. Int J Epidemiol 2002; 31(2):336-341.

11. Ben-Shlomo Y, Kuh D. A life course approach to chronic disease epidemiology: conceptual models, empirical challenges and interdisciplinary perspective. Int J Epidemiol 2002; 31:285-293.

12. Hertzman C, Power C, Matthews S, Manor O. Using an interactive framework of society and lifecourse to explain selfrated health in early adulthood. Social Science \& Medicine 2001; 53:1575-1585.

13. Bartley M. Health inequality: introduction to theories, concepts and methods. Cambridge: Polity; 2004.

14. Blane D. Health inequalities: from science to policy. In: Oliver A, editor. Personal histories in health research. London: Nuffield; 2005.

15. Ljung R, Hallqvist J. Accumulation of adverse socioeconomic position over the entire life course and the risk of myocardial infarction among men and women: results from the Stockholm Heart Epidemiology Program (SHEEP). $J$ Epidemiol Community Health 2006; 60(12):1080-1084.

16. Singh-Manoux A, Ferrie JE, Chandola T, Marmot M. Socioeconomic trajectories across the life course and health outcomes in midlife: evidence for the accumulation hypothesis? Int J Epidemiol 2004; 33(5):1072-1079.

17. Pollitt RA, Rose KM, Kaufman JS. Evaluating the evidence for models of life course socioeconomic factors and cardiovascular outcomes: a systematic review. Bmc Public Health 2005; 5.

18. Schoon I, Sacker A, Bartley M. Socio-economic adversity and psychosocial adjustment: a developmental-contextual perspective. Social Science \& Medicine 2003; 57(6):1001-1015.

19. Elder GH. Family History and the Life Course. In: Hareven T, editor. Transitions: The Family and the Life Course in a Historical Perspective. New York: Academic Press; 1978. 
20. Elder GH. Perspectives on the life course. In: Elder GH, Jr., editor. Life course dynamics: trajectories and transitions, 1968-1980. New York: Cornell University Press; 1985. 23-49.

21. Hareven TK, Trepagnier B. Families, history, and social change: life course and cross-cultural perspectives. Westview Press Boulder, CO; 2000.

22. Beck U. Risk society: towards a new modernity. London: Sage; 1992.

23. Wadsworth ME, Bynner J. A Companion to Life Course Studies: the social and historical context of the British birth cohort studies. Taylor \& Francis; 2011.

24. Arber S, Gilbert GN, Dale A. Paid employment and women's health: a benefit or a source of role strain? Sociology of Health \& Illness 1985; 7(3):375-400.

25. Martikainen P. Women's employment, marriage, motherhood and mortality: a test of the multiple role and role accumulation hypotheses. Social Science \& Medicine 1995; 40(2):199-212.

26. Goode WJ. A theory of role strain. American sociological review 1960;483-496.

27. Lahelma E, Arber S, Kivela K, Roos E. Multiple roles and health among British and Finnish women: the influence of socioeconomic circumstances. Social Science \& Medicine 2002; 54(5):727-740.

28. Fokkema T. Combining a job and children: contrasting the health of married and divorced women in the Netherlands? Social Science \& Medicine 2002; 54(5):741-752.

29. Sieber SD. Toward a theory of role accumulation. American sociological review 1974;567-578.

30. Read S, Grundy E. Mental health among older married couples: the role of gender and family life. Social Psychiatry and Psychiatric Epidemiology 2011; 46(4):331-341.

31. Read S, Grundy E, Wolf DA. Fertility history, health, and health changes in later life: A panel study of British women and men born 1923ГÇô49. Population Studies 2011; 65(2):201-215.

32. Finch N. Why are women more likely than men to extend paid work? The impact of workГÇôfamily life history. European Journal of Ageing 2014; 11(1):31-39.

33. Moen P, Dempster-McClain D, Williams Jr RM. Successful aging: A life-course perspective on women's multiple roles and health. American Journal of Sociology 1992;1612-1638.

34. Lyberaki A, Tinios P, Papadoudis G. Retrospective explanation of older women's lifetime work involvement: Individual paths around social norms. Advances in Life Course Research 2013; 18(1):26-45.

35. Leoni T, Eppel R. Women's Work and Family Profiles over the Lifecourse and their Subsequent Health Outcomes. Evidence for Europe. 2013. WWW for Europe Working Paper.

36. Mossey JM, Shapiro E. Self-rated health: a predictor of mortality among the elderly. American Journal of Public Health 1982; 72(8):800-808.

37. Singh-Manoux A, Martikainen P, Ferrie J, Zins M, Marmot M, Goldberg M. What does self rated health measure? Results from the British Whitehall II and French Gazel cohort studies. J Epidemiol Community Health 2006; 60(4):364-372.

38. Berney LR, Blane DB. Collecting retrospective data: Accuracy of recall after 50 years judged against historical records. Social Science \& Medicine 1997; 45(10):1519-1525.

39. Ward K, Medina J, Mo M, Cox K. ELSA Wave Three: Life History Interview. A User Guide to the Data. 2009. London, NatCen.

40. Abbott, A., Tsay A. Sequence analysis and optimal matching methods in sociology - Review and prospect. Sociological Methods \& Research 2000; 29(1):3-33. 
41. Abbott, A., Hrycak A. Measuring resemblance in sequence data: an optimal matching analysis of musicians' careers. The American journal of sociology 1990; 96(1):144-185.

42. Erikson R, Goldthorpe JH. The constant flux : a study of class mobility in industrial societies. Oxford: Clarendon Press, 1992.

43. Joshi H. Production, reproduction, and education: Women, children, and work in a British perspective. Population and Development Review 2002; 28(3):445-474.

44. Ni Bhrolchain M. The interpretation and role of work-associated accelerated childbearing in post-war Britain. European Journal of Population 1986; 2(2):135-154.

45. McMunn A, Bartley M, Hardy R, Kuh D. Life course social roles and women's health in mid-life: causation or selection? J Epidemiol Community Health 2006; 60(6):484-489.

46. Evandrou M, Glaser K. Family, work and quality of life: changing economic and social roles through the lifecourse. Ageing \& Society 2004; 24(05):771-791. 
Figure 1: Trajectories of economic activity over the life course from age 16-64 among women aged 64+ at interview, according to OMA cluster.
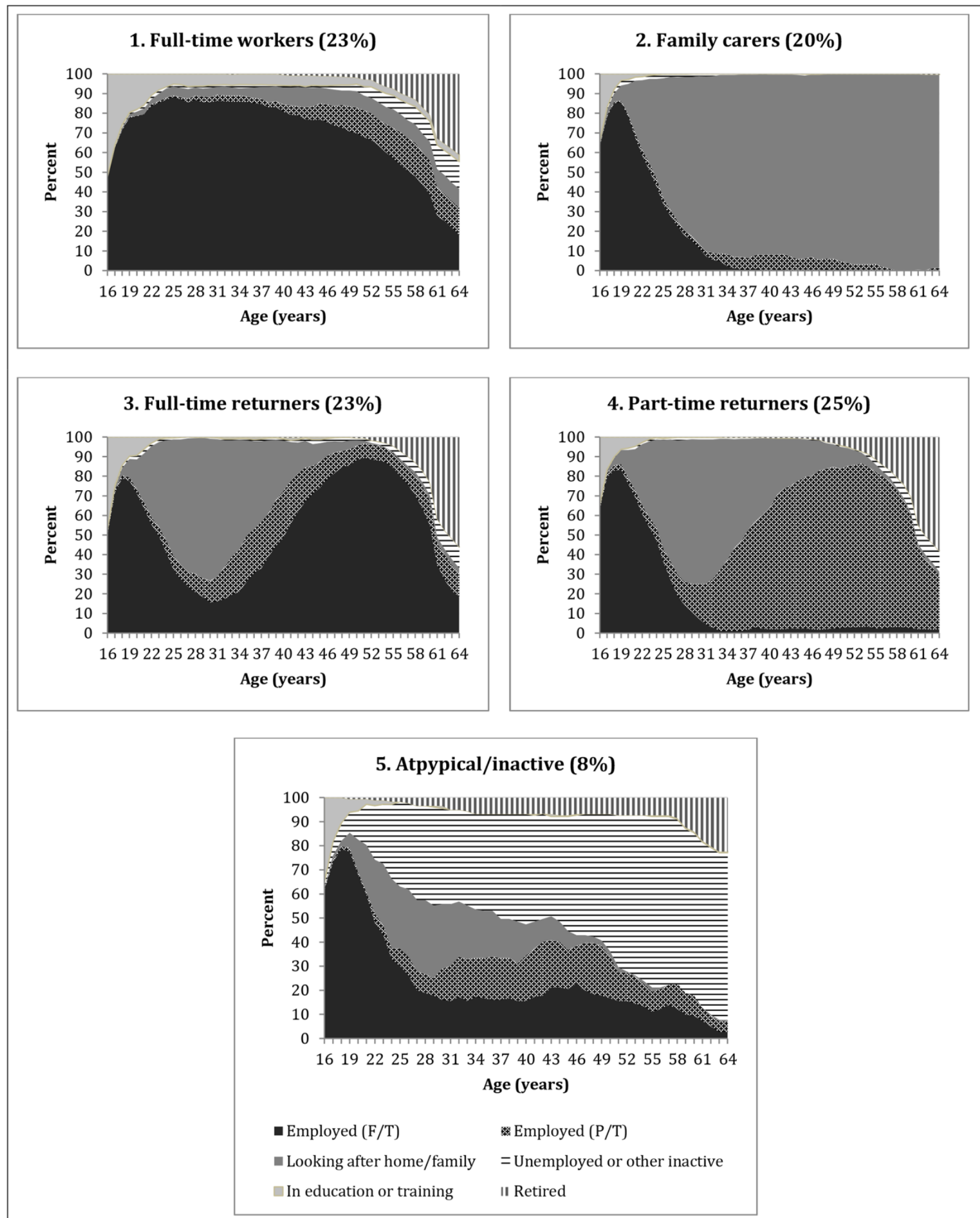